\title{
Research of the Measurement of Patent-intensive Industry Technology Lock-in from the Perspective of TML
}

\section{Wu Yang}

University of Science and Technology Beijing https://orcid.org/0000-0003-0376-9141

Shiqiang Sun ( $\sim$ sun9330@126.com )

University of Science and Technology Beijing https://orcid.org/0000-0002-1891-0745

Tengfei Gao

Beijing University https://orcid.org/0000-0001-9109-8215

\section{Research Article}

Keywords: TML Model, Patent-intensive Industries, Technology Lock-in, Growth Rate Cycle Index Synthesis

Posted Date: September 7th, 2021

DOl: https://doi.org/10.21203/rs.3.rs-863678/v1

License: (c) (i) This work is licensed under a Creative Commons Attribution 4.0 International License. Read Full License 


\title{
Research on the Measurement of Patent-intensive Industry Technology
}

\section{Lock-in from the Perspective of TML}

\begin{abstract}
As the core industry of technological innovation capabilities, patent-intensive industries, cultivating their rapid development is conducive to breaking the "technological lock-in" and realizing my country's independent innovation in the core technology field. Based on the INNOJOY patent database, the wireless communication network patent was selected as the research object, and the subjective and objective weighting method and the growth rate cycle index synthesis method were used to measure the technical lock-in from the perspective of TML. The study found: (1) The technology lock-in index of the United States, Japan, and South Korea generally shows an upward trend, while the technology lock-in index of China has a trend of declining volatility, and the United States has the highest degree of lock-in in the field of wireless communication network technology, ranking first. Japan is in the second position, South Korea is in the third position, and China is in the fourth position; (2) The six core technologies identified belong to American companies. The public years are concentrated in 2017 and 2019, and the technical field is concentrated in H04W72/04 ( The same data transmission method and user equipment), H04W72/08 (signaling for proximity service and D2D discovery in LTE networks), and H04L1/00 (method to support channel allocation information for uplink and downlink channels) And these three core patents show that the current three core technologies are cutting-edge technologies in the field of wireless communication networks.
\end{abstract}

Keywords: TML Model, Patent-intensive Industries; Technology Lock-in; Growth Rate Cycle Index Synthesis

\section{Introduction}

The rapid development of patent-intensive industries has become an important way for the country to improve its technological innovation capabilities and expand the creation and application of intellectual property rights. Since the beginning of the 21 st century, developed countries have introduced a series of intellectual property strategies and policies to promote the protection of their own innovations in order to consolidate their leading position in the world economic development. In April 2012, the U.S. Department of Commerce and the Patent and Trademark Office jointly issued the "Intellectual Property and the U.S. Economy: Industry Focus" report, defining industries with above-average intellectual property rights as "intellectual property-intensive industries." In order to strengthen the protection of intellectual property rights internally and to formulate and adjust international intellectual property rules offensively externally, in 2016, the United States issued "Intellectual Property and the U.S. Economy: 2016 Update", the European Patent Office (EPO) and the European Union Intellectual Property Office (EUIPO) also jointly issued the "Intellectual Property Intensive Industries and Their Economic Performance in the EU"( Garcilazo, Monroy, Martins,2021). Compared with foreign countries, China's patent-intensive industries started late. In 2018, the value-added of patent-intensive industries accounted for $11.6 \%$ of GDP, which marked the official establishment of China's patent-intensive value-added accounting and release mechanism. In 2019, according to the "Statistical Classification of Intellectual Property (Patent) Intensive Industries (2019)", it was calculated that the proportions of information and communication technology manufacturing and information technology service industries in patent-intensive industries were $20.1 \%$ and $18.2 \%$, 
respectively, which shows that China's ICT plays an important role in patent-intensive industries.

However, in the development period of economic globalization, in order to maintain their monopoly position, multinational companies have implemented a "technical blockade" strategy against China. However, the development of a new generation of information technology has shortened the technology life cycle, and thus has more channels for obtaining information, which has made the blockade less effective. In order to maintain the technology gap, multinational companies have adjusted their "blockade" strategy to a "lock-in" strategy, which is manifested in the following two aspects: first, the lock-in of core technologies, and the external resale of non-core technologies; second, the technical track lock-in, dumping low-end products and their production chain (take Euv lithography machine as an example). As a result, a series of "stuck neck" problems have been triggered in China, forcing the formation of technological dependence on developed countries (Liu, Chen, Tang et al,2021). How to break the "technical lock" of foreign economies to China has become a key issue that must be resolved. However, there are few documents that have studied the combination of patent-intensive industries and technology lock-in. They focus on unilateral research. For example, in patent-intensive industries, they mainly focus on dynamic efficiency ( $\mathrm{Li}$, Wang, 2020; Wang, Liu, Chen, 2021) and the intensity of judicial protection (He, Dong, 2020; Feng, Ma, 2019) , R\&D investment (Gilbert,2019; Mo,2021) and other aspects; in terms of technology lock-in, it is mainly from technical entanglement (Zhao, Du,2020; Ejderyan, Ruef, Stauffache, 2020) , technical power(Sun, Shi, Yu, 2019) and technology spillover(Wang, Zhang, 2019). Based on this, this paper constructs a technology-market-law three-dimensional model, adopts the growth rate cycle index synthesis method, and selects wireless communication network patent technologies in China, the United States, Japan, and South Korea as the research objects, and clarifies the formation mechanism of technology lock-in, and conducted measurement research to provide a theoretical basis and analysis method for cracking China's "technical lock-in", and then achieve the goal of "patent power".

\section{Research Foundation and Theoretical Development}

\subsection{Research Status of Patent-intensive Industries}

Patent-intensive industries are based on the protection of the patent system. Through the investment of innovative knowledge, they form a knowledge-intensive industry that has a high-density patent level and can continue to obtain operational value. In April 2012, the U.S. Department of Commerce and the Patent and Trademark Office jointly issued the "Intellectual Property and the U.S. Economy: Industry Focus" report, which defined industries with higher than average intellectual property intensity (number of patents granted/average employment) as "intellectual property intensive industries"(Fehder, Murray, Stern, 2014). Since then, the research on patent-intensive industries has developed rapidly, and its research dynamics can be divided into the following three parts: First, the definition of the concept of patent-intensive industries is mainly based on the two standards of patent density and patent scale, and relying on innovative knowledge to participate to market competition and excess returns. In 2013, the European Union Intellectual Property Office (EUIPO) judged whether it is a patent-intensive industry by comparing the number of patents used by the average number of employees in the industry with the industry average. In the same year, the China Intellectual Property Office adopted the number of patents granted per person employed within five years as a measure of patent-intensive industries. In the past, scholars defined the concept of patent-intensive industries too much and focused on patent density (Li, 2020; Qi X, Feng, 2015; Fischer, Ringler, 2015). However, this 
article believes that high-quality patents are the core technical elements that constitute technology lock-in. Therefore, the concept of patent-intensive industries should include patent density and patent quality; Second, the research on the measurement of the contribution of patent-intensive industries to economic growth. Taking the 2019 EU Intellectual Property Research Report as an example, its patent-intensive industries accounted for $16.1 \%$ of GDP, which greatly promoted its economic development. In 2018, China announced for the first time that the added value of patent-intensive industries accounted for $11.6 \%$ of GDP, and its contribution to GDP growth was $15.7 \%$. This indicates that Chhinese patent-intensive industries play an important role in national economic development. Third, research on the strategic path and countermeasures for the development of a powerful country with patent-intensive industries. Based on the perspective of the patent protection system, comparing the differences between the patent systems of China and the United States and their economic growth, it is concluded that a sound patent protection system is a characteristic of a strong patent-intensive industry ( $\mathrm{Li}, \mathrm{Chen}, 2017)$. Du Chuanzhong and Wang Mengchen (2021) established an open economic model of skilled labor, intellectual property protection, and value chain division of labor, and concluded that technological advancement under the protection of intellectual property rights has multi-dimensional characteristics in the promotion of the manufacturing value chain ( $\mathrm{Du}$, Wang, 2021). An important standard for patent-intensive industries is to have typical high-quality patents and be able to commercialize them. Patent-intensive industries, as intellectual property-driven innovation-driven industries characterized by high growth, high technology and high added value, not only involve technological change and innovation, and the development of patent legal protection systems, but are also an important driving force for the development of industrial economy.

Through combing and summarizing the existing research, this article believes that patent-intensive industries have three characteristics: First, technical characteristics, that is, the citation relationship of the technology and the IPC distribution field, reflecting the industry's mastery of a certain technology and future technological development trends; second, market characteristics, emphasizing whether a certain technology can obtain excess returns for enterprises in a competitive market and whether it contributes to the economic growth of the country/region; third, legal characteristics, attention the main point is the legal protection period and geographical protection of patented technology, which protects the legitimate rights and interests of patented inventors to a certain extent. In summary, this article believes that patent-intensive industries are knowledge-intensive industries based on the protection of the patent system that form a high-density patent level and continue to obtain operational value by investing in innovative knowledge.

\subsection{Technology Lock-in Under the TML Model}

Lock-in refers to a stable state in which the system presupposes the rejection of other alternative solutions. Arthur (1989) introduced it into the theory of technological innovation and proposed that technological lock-in is an equilibrium state of economic decision-making failure caused by technological dependence (core technological dependence and technological path dependence) (Arthur, 1989). Unless there are enough external stimulus factors, this equilibrium state will continue for a long time with the previous technological development path (the core technology/technological path has been locked in this state for a long time), and even the phenomenon of "Good products are eliminated, bad products survive" may appear (David, 1985). The existing research on technology lock-in is mainly divided into three categories: First, core 
technology lock-in. Such research mainly focuses on the definition and measurement of core technologies. The core technology is the technology that determines the quality of technical products and the control technology system in the technical system. Yang Wu (2021) believes that core technology has three characteristics: technology, economy, and law. As the basis for the development of the entire technology system, core technology is a key component of the technology system. The core technology is the technical foundation that constitutes the technical product and quality. The core technology must undergo property rights to form a monopoly, which is also the legal basis for technology lock-in; second, technology path lock-in. Take the lithography machine of the Dutch ASML company as an example. ASML and its main shareholders Intel, Samsung and TSMC (TSMC) have formed an industrial interest alliance. With these alliances, ASML has been monopolizing high-end products and technologies in different periods in the field of the most advanced EUV (extreme ultraviolet) lithography machine. Starting from the $1500 \mathrm{~nm}$ technology of the first generation lithography machine process node in 1978, along with the fourteen generations of technology along $800 \mathrm{~m}, 500 \mathrm{~nm}, 350 \mathrm{~nm}, 250 \mathrm{~nm}, 180 \mathrm{~nm}$, $130 \mathrm{~nm}, 90 \mathrm{~nm}, 65 \mathrm{~nm}, 45 \mathrm{~nm}, 32 \mathrm{~nm}, 22 \mathrm{~nm}, 14 \mathrm{~nm}, 7 \mathrm{~nm}$, ASML Alliance not only monopolizes the core technology at each stage (forming the core technology lock-in), but also monopolizes the core technology on the entire lithography machine process node technology path (forming the entire technology path lock-in); third, the technical standard lock-in . For example, in the field of communication technology, China has nothing in the $1 \mathrm{G}$ and $2 \mathrm{G}$ eras, and all core technologies are monopolized in the hands of the United States, Europe, Japan and South Korea. While forming core technology locks and technology path locks to China. However, in the 3G era, China has entered the technology to follow, the $4 \mathrm{G}$ era basically runs side by side, and the $5 \mathrm{G}$ era begins to lead. At present, among the $455 \mathrm{G}$ standards approved, there are as many as 21 in China. In particular, China has also formed the $5 \mathrm{G}$ alliance composed of dozens of companies or institutions, and has built the "ecosystem" of China's $5 \mathrm{G}$ technical standards, which has completely broke all the foreign technology lock-in modes of China in the $5 \mathrm{G}$ field.

Based on the theory of technological innovation, this article believes that technological lock-in is the result of a combined effect of multiple factors, which involves the transformation and innovation of technology itself, but also includes the drive of the market economy, and is also restricted by the intellectual property protection system. Therefore, this article will study the decoupling of technology lock-in based on the theory model of technology-market-law integration (ie the TML model): First, at the technical level, it can be known from the equilibrium theory that before the market reaches the equilibrium point, a certain that the more patents a technology obtains, the easier it is to be accepted by various market entities, that is, the lock-in effect of the technology on the market will gradually increase. Although the self-reinforcing mechanism will enhance the lock-in effect on a certain technology, it will hinder the production and development of new technologies. From the law of "technology-system" change, we can see that both technological innovation and institutional change must abide by the time rule, but the two are not synchronized (that is, the speed of technological innovation is faster than the speed of institutional change). When a competitor in the market owns a certain leading technology (the technology is at the limit of technological progress obtained in the process of developing to a specific period), other participants will try to find alternative technologies in a higher technological limit by citing existing technologies. Based on this, this article measures the technical elements in technology lock-in from indicators such as the number of patent citations and the number of IPC parts; second, 
at the market level, The theory of increasing returns believes that when a certain patented technology forms a scale effect in the market, it will bring stable and increasing returns to its owners. The dependence on core technology (technical path) determines the future evolution direction of the economic system. Once a certain patented technology is locked in the market, the difficulty of technological transition is multiplied. In the multi-party technology market, through the implementation of its own technical standards, to strengthen its own monopoly position, technology chasers can easily fall into the trap of passive lock-in. Take the ASML high-end lithography machine as an example. The alliance has strictly controlled the sale of high-end lithography machines to China, and it has strongly promoted the sale of low-end lithography machines (mainly 22nm lithography machines) and chips, and maintained 1-2 the technological gap between the new generations has caused China to be "stuck" in core technology and fall into a vicious circle of "introduction-backward, reintroduction-backward again". Based on this, this article measures market factors from indicators such as the number of the same family and the remaining validity period; third, at the legal level, technology lock-in reflects the legal protection of intellectual property rights such as patents based on product competition, and its essence is competition for obtaining patents and other property rights granted by law. According to the space model of patent property rights, as shown in Figure 1,

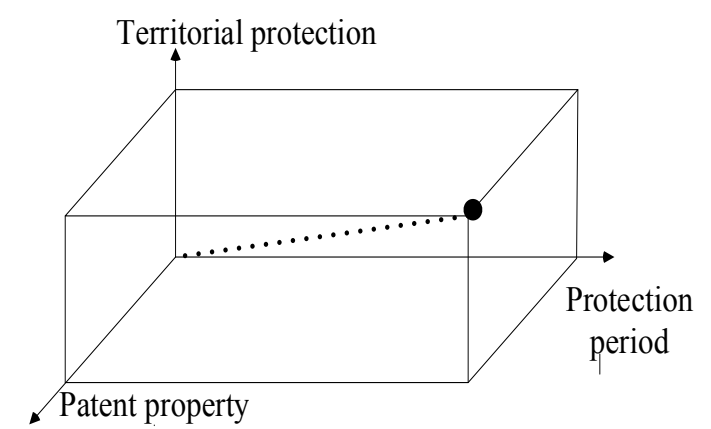

Figure 1 The spatial model of patent property rights

Technology lock-in from the legal perspective can be studied from two aspects: (1) The legal protection period. The "Patent Law" stipulates that the effective protection period of invention patents is 20 years. However, many of China patented technologies were abandoned in less than 10 years. The electronic field is a typical representative, and the average time is $1-2$ years. One of the main reasons is that the patent level is low and the elimination rate is relatively fast; (2) Geographical protection. According to international intellectual property rules, the property rights of a certain patent are only protected in the country/region of the application, but not legally effective in other regions. The main reasons for this are the cost of patent maintenance, the state of technological competition in the area of property rights, and the market scope of the area of property rights. Daghfous and White (1994) summarized the information in the process of "technology-market" innovation as the third element, thinking that it is a comprehensive reflection of technology elements and market elements (Daghfous, White, 1994). Saito Yu (1990) found that technical elements (38.82\%), market elements (38.25\%) and legal elements $(18.87 \%)$ are the core elements of technological innovation projects (Saito, 1990). However, the information itself does not have independent essential characteristics. It needs to be included in the field of intellectual property law to better study the logical relationship and dynamic evolution of technology locking, and use indicators such as patent legal status and PCT international applications to measure legal elements.

\section{Quantitative Models and Measurement Methods}

\subsection{Quantitative Model}

Through the research and analysis of technology lock-in, this article believes that technology lock-in has three principles, namely the basic principle, the systematic principle and the exclusive 
principle. One is the basic principle. As the core element of technology lock-in, technical elements mainly select the number of citations, the number of citations by examiners, the number of cited patents and other indicators (Zhang, Li, Guo, 2019; Marco, Myriam, Salvatore, 2019; Yang, Sun, $\mathrm{Xu}, 2021)$. Technology lock-in has high R\&D investment, long R\&D cycle, and knowledge silence. These characteristics indicate that technology lock-in has a high level of scientific foundation and difficulty in innovative research and development, and it is difficult to be surpassed by subsequent technologies. "The core technology is based on the development of the industrial technology system" emphasizes the systematic and basic nature of technology lock-in, which is its first essence. This article summarizes it as the fundamental nature of technology lock-in; second, the systemic principle. The market element is the economic goal of technology lock-in. It mainly selects indicators such as the number of the same family, the number of countries in the layout, and whether it is tripartite patent (Abernathy, Utterback, 1975; Rosenbloom, Abernathy, 1982); The formation of technology lock-in and the generation of technology lock-in depend on the technology market system and market ecological environment. The development of technology lock-in extension into peripheral supporting application technologies and the formation of a technology market system around core technologies is a necessary condition for technology lock-in to play a role. Therefore, technology lock-in emphasizes the role of its technology market system, which is systematic; third, the principle of exclusivity. Legal elements are the fundamental guarantee for technology lock-in (He, Dong, 2020). According to the space model of patent property rights, we mainly select the number of rights, the number of unique rights, the survival period, whether PCT international applications and the current legal status are indicators (He, Dong, 2020; Danielle, Charlotta, Jan, 2015). In industrial technology competition, technology is the carrier, economic benefits are the goal, and the law is the means to protect benefits. The overall performance of technology lock-in is that it has a competitive advantage compared with general technology. The systematic and basic nature of technology lock-in is the prerequisite for its exclusivity. The key effect on product function and quality is its exclusive performance. Exclusive monopoly is the guarantee to maintain its competitive advantage. In summary, technology lock-in has the characteristics of system, basic and exclusivity. Based on the three principles of technology lock-in, the basic principle, the system principle and the principle of exclusivity, in terms of technical elements, indicators such as the number of citations and IPC subclass numbers are selected; in terms of market elements, indicators such as the number of the same family and tripartite patents are selected; In terms of legal elements, indicators such as the number of weights and the number of independent weights are selected to construct the technical locking measurement indicators under the TML model, as shown in Figure 2. 


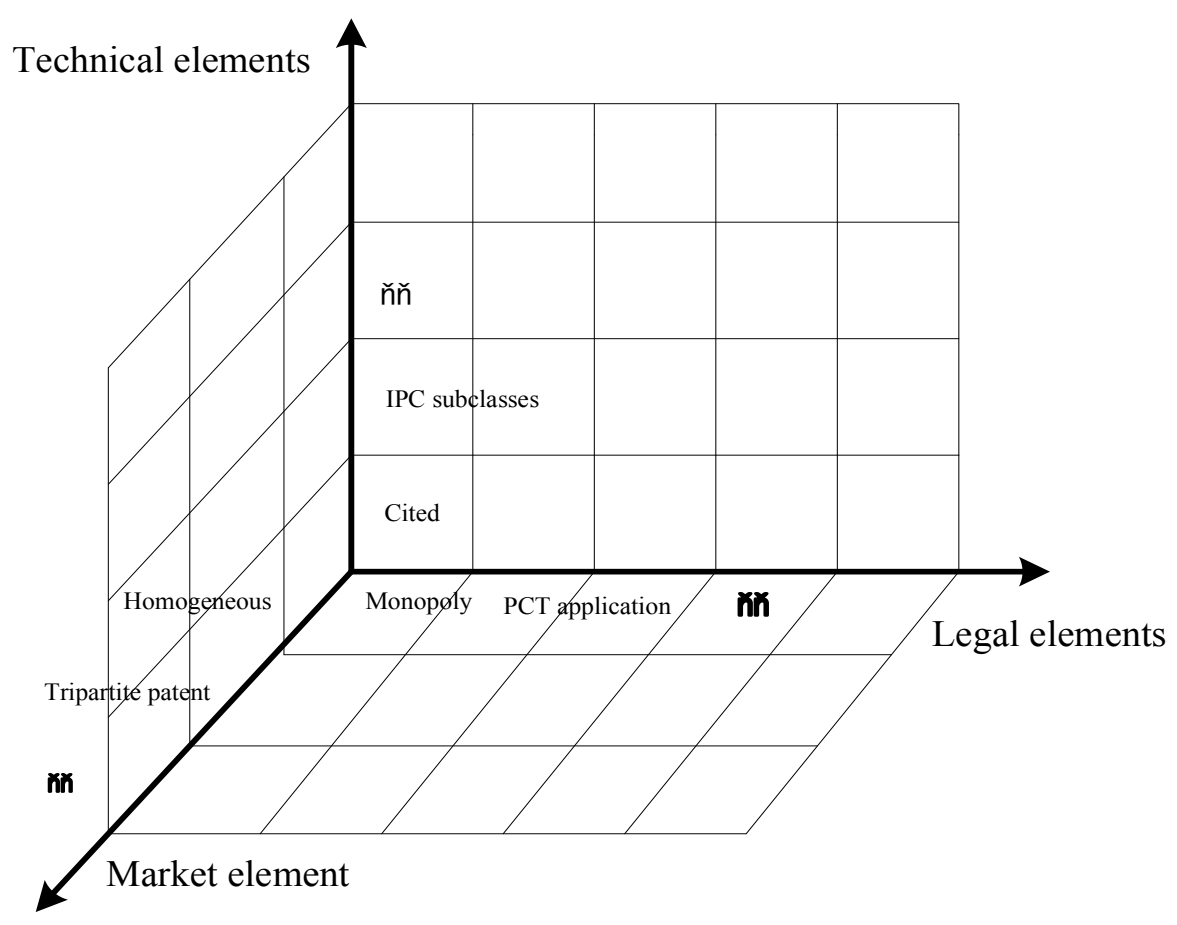

Figure 2 TML three-dimensional model diagram

\subsection{Measurement Method}

\subsubsection{Delphi Method}

The Delphi method uses five levels, with "high" representing 100 points, "higher" representing 75 points, "medium" representing 50 points, "low" representing 25 points, and "lower" representing 0 points. By issuing questionnaires to 5 experts and passing 4 rounds of scoring, the weights of secondary indicators are determined based on the results and expert scoring. The weight formula is as follows:

$$
W_{j}=\frac{100 * N_{1}+75 * N_{2}+50 * N_{3}+25 * N_{4}+0 * N_{5}}{\sum_{i=1}^{5} N_{i}}
$$

In the formula, $\mathrm{Wj}$ is the weight of the secondary index, where $\mathrm{j}=1,2,3$, corresponding to technical elements, market elements and legal elements, respectively; N1 to N5 represent the scores of 5 experts in related fields.

The coefficient of variation method is used to assign weights to the three-level indicators, which effectively eliminates the differential influence of different dimensions. In formula (2), Xi is the original data of the $\mathrm{i}$-th three-level index, $\mu$ is the average value of the $\mathrm{i}$-th three-level index, and CVi in formula (3) is the coefficient of variation of the i-th three-level index.

$$
\sigma_{i}=\sqrt{\frac{\sum_{i=1}^{n}\left(X_{i}-\mu\right)^{2}}{n}}
$$

$$
C V_{i}=\sigma_{i} / \mu
$$

Calculate the weight $\omega$ i of the i-th evaluation index,

$$
\omega_{i}=C V_{i} / \sum_{i=1}^{n} C V_{i}
$$




\subsubsection{Growth Rate Cycle Index Synthesis}

The growth rate cycle index synthesis method is to reflect the fluctuation of the index by the growth rate, and to further observe the growth rate of the index by calculating the ratio of the data of the same period of this year and the previous year (Yang, Sun, Xu, 2021). Because this article uses annual data between countries, and most of the data shows a growth trend. Therefore, in order to make a more comprehensive and comprehensive analysis of the relative fluctuations locked in technology, this article adopts the growth rate cycle index synthesis method to measure, the method is as follows:

(1) Calculate the year-on-year growth percentage rij of a single indicator, the formula is as follows:

$$
r_{i j}=Y_{i j}(t)-Y_{i j}(t-1), t=2,3, \ldots, n
$$

Where rij is the year-on-year growth percentage of the $\mathrm{i}$-th third-level index of the $\mathrm{j}$-th second-level index, and Yij(t) is the t-th original data of the $\mathrm{i}$-th third-level index of the $\mathrm{j}$-th second-level index, $\mathrm{j}=1,2,3, \mathrm{i}=1,2,3, \ldots \ldots, \mathrm{n}$.

(2) Calculate the weighted sub-item composite index Ij(t)

$$
I_{j}(t)=\frac{\sum_{i=1}^{n} r_{i j} * \omega_{i}}{\sum_{i=1}^{n} \omega_{i}}, j=1,2,3
$$

Where $\omega \mathrm{i}$ is the three-level index weight

(3) Calculate the weighted total index I $(\mathrm{t})$

$$
I(t)=\sum_{t=2}^{n} I_{j}(t) * \omega_{j}
$$

In the formula, $\mathrm{Wj}$ is the weight of the secondary index, $\mathrm{j}=1,2,3$, which are the weights of technical factors, market factors and legal factors respectively, and the sum of their weights is 1 .

(4) Calculate the smoothed total index, I(t) takes I(2010) as the base period, set the initial value to 100 , and calculate the total index for each year through three moving averages. $I(t) "$ is the initial smoothed index, and $\mathrm{I}(2010) "$ is the smoothed index of $\mathrm{I}(2010)$. $\mathrm{t}$ year adjustment $=[\mathrm{t}$ year original number $* 2+(\mathrm{t}+1)$ year original number $] / 3 ; \mathrm{t}+1$ year adjustment number $=[(\mathrm{t}+1)$ year original number*2+(t+2)year Original number*2]/3; $\mathrm{t}+2$ year adjustment number $=[\mathrm{t}$ year original number $+(t+1)$ year original number*2+(t+2)year original number*3]/6. By analogy, find the final total index.

$$
I(2010)=100 \quad(8) \quad I(t)=\frac{I(t) "}{I(2010)} \times 100
$$

\subsubsection{Identification of Core}

Technology

and

\section{Determination of the Degree of Lock-in}

Regarding the identification of core patents, this article uses the method of Yang Wu, Sun Shiqiang, and Xu Hongdan (2021)to set the maximum value of the weighted total score (TS) of patents as the benchmark value (ie maxTS), where The range of core patents is greater than or equal to $70 \%$ maxTS, the range of key patents is greater than or equal to $30 \%$ maxTS and less than $70 \% \operatorname{maxTS}$, and the range of general patents is less than $30 \%$ maxTS. The specific classification 
interval is shown in Table 1:

Table 1 Patent classification interval

\begin{tabular}{ll}
\hline Patent interval & Patent type \\
\hline$[70 \%, 100 \%]$ & Core patent \\
{$[30 \%, 70 \%)$} & Key patent \\
{$[0 \%, 30 \%)$} & General patent \\
\hline
\end{tabular}

Based on the research of Gong Rizhao and Pan Fenping (2020), this paper adopts the law of uniform distribution function to construct the interval number ranking standard of the degree of technical lock-in, as shown in Table 2.

Table 2 Standards for the degree of technical lock-in

\begin{tabular}{|c|c|c|c|c|c|}
\hline Degree of lock-in & Low lock & Lower lock & Moderately locked & Higher lock & Height lock \\
\hline Lock value & $85.00-92.00$ & $92.01-99.00$ & $99.01-106.00$ & $106.01-113.00$ & $113.01-120.00$ \\
\hline
\end{tabular}

\section{Empirical Analysis}

\subsection{Data Source and Scope}

As the core technology for the development of the information and communication industry, wireless communication network is a key area of key research in countries all over the world. Based on the innojoy patent database, the search method using the combination of the keyword "wireless communication network" and the IPC classification number "H04W" is set to be published between January 01, 2010 and February 01, 2020 (Patent substantive examination takes 18 months), and the top four countries (China, the United States, Japan, and South Korea) for patent disclosures are selected. A total of 77,966 valid patent data are in line with the data requirements of this article.

\subsection{Indicator Weighting Results}

Based on the TML three-dimensional model, subjective and objective methods are used to weight the indicators, and the weight results are obtained, as shown in Table 3.

Table 3 Indicator weighting results

\begin{tabular}{|c|c|c|c|c|}
\hline $\begin{array}{l}\text { First level } \\
\text { indicator }\end{array}$ & $\begin{array}{l}\text { Secondary } \\
\text { indicators }\end{array}$ & Three-level indicators & Weights & references \\
\hline \multirow{12}{*}{$\begin{array}{c}\text { Technology } \\
\text { lock }\end{array}$} & \multirow{8}{*}{$\begin{array}{l}\text { Technical } \\
\text { elements } \\
(0.4)\end{array}$} & Cited & 0.2019 & \\
\hline & & Cited by the examiner & 0.1950 & Liu,Chen, Tang et al(2020) \\
\hline & & Cited patent & 0.2374 & Zhang Mier, Li Haipeng and \\
\hline & & Citing patent country & 0.0617 & Guowei (2019); Marco, \\
\hline & & non-patent & 0.2515 & Myriam, Salvatore (2019); \\
\hline & & literature & & Yang Wu, Sun Shiqiang, Xu \\
\hline & & IPC Department & 0.0116 & Hongdan (2021) \\
\hline & & IPC subclass & 0.0409 & \\
\hline & \multirow{4}{*}{$\begin{array}{l}\text { Market } \\
\text { elements } \\
(0.3)\end{array}$} & Remaining & 0.4425 & Feng, Ma(2019); Qi, \\
\hline & & period & & Feng(2015); \\
\hline & & Homogeneous number & 0.3008 & Abernathy and Utterback \\
\hline & & $\begin{array}{l}\text { Number of Layout } \\
\text { Countries }\end{array}$ & 0.1341 & $\begin{array}{c}\text { (1975); Rosenbloom, } \\
\text { Abernathy (1982) }\end{array}$ \\
\hline
\end{tabular}




\begin{tabular}{llll} 
& Tripartite Patent & 0.1226 & \\
& Number of weights & 0.1227 & \\
& Monopoly & 0.1186 & \\
Segal & Manual pages & 0.0820 & \\
elements & Survival period & 0.1663 & He Ningxin, Dong Zhelin \\
(0.3) & Number of countries in & 0.1013 & Stem (2014); Danielle, \\
& the layout of INNOJOY & & Charlotta, Jan, Per (2015) \\
& PCT international & 0.0546 & \\
& application & & \\
& Current legal status & 0.0548 & \\
\hline
\end{tabular}

\subsection{Measurement Results}

It can be seen from Figure 3 that the technical factor indexes of China and the United States show a downward trend in volatility, while the technical factor indexes of Japan and South Korea have the characteristics of rising volatility. Among them, China reached a band peak in 2013, after which volatility declined. In 2011, there were 314,000 registered users in the instant messaging market of China's Internet companies, a year-on-year increase of 45.4\% ("2011-2012 China Internet Enterprise Instant Messaging Industry White Paper"). In 2013, the implementation of the "Broadband China" strategy clearly defined the important position of the broadband development path at the national level, which has been promoted to promote the development of the broadband industry chain. In December 2013, the 4G operation license (based on the TD-LTE standard) and the issuance of the first batch of virtual operator licenses represented that China has officially entered In the 4G era, this move has greatly promoted the vigorous development of China's wireless communication network. However, the 2014 statistical annual report released by the Ministry of Industry and Information Technology pointed out that the revenue growth rate of the wireless communication industry is consistent with the user growth rate, which indicates that this field has entered the relatively saturated new normal (that is, the status of the wireless communications industry in the national economy will continue to shrink), coupled with the patent war between foreign economies and China (take Huawei as an example) and the blockade of core technologies, this has further led to greater difficulties for my country to make independent technological breakthroughs in the wireless communications industry. In 2013, the United States developed the "environmental scattering communication" technology in the data communication professional group of the Association for Computing Machinery (ACMSIGCOMM), which can send and receive information in an environment without power. The emergence of technology has greatly promoted the development of the US radio communication industry. In 2015, the US government vigorously promoted cloud computing, IPV6 and virtualization technology and other fields, and applied new technologies (sensor information technology, predictive analysis, and machine learning, etc.) to improve the efficiency of the use of information technology resources. The technological elements of Japan and South Korea have shown a trend of rising volatility. Among them, in 2012, South Korea upgraded the Internet infrastructure to increase the broadband connection speed to $100 \mathrm{Mbps}$ (the speed in the United States was $5 \mathrm{Mbps}$ at the time), which has greatly promoted the development of the wireless communication industry in South Korea. In 2015, the emergence of new technologies such as cloud computing and IPV6 greatly promoted the 
development of wireless communication technologies in Japan and South Korea, and each reached a relative peak. 2018 Three major changes have taken place in the wireless communications industry in 2004: First, the integration of wireless networks and wired networks to achieve the centralized release of optical fiber technology and the strategic deployment of cloud RAN (C-RAN) architecture; Second, the opening of the $3.5 \mathrm{GHz}$ frequency band has prompted LTE (Long Term Evolution) networks to converge in licensed spectrum and unlicensed spectrum; the third is the widespread application of $5 \mathrm{G}$ in logistics, manufacturing, and medical and other new-generation Internet of Things (loT). The above three changes have prompted the United States , Japan, South Korea reached a peak in 2018, while China only reached a relative peak in 2019.

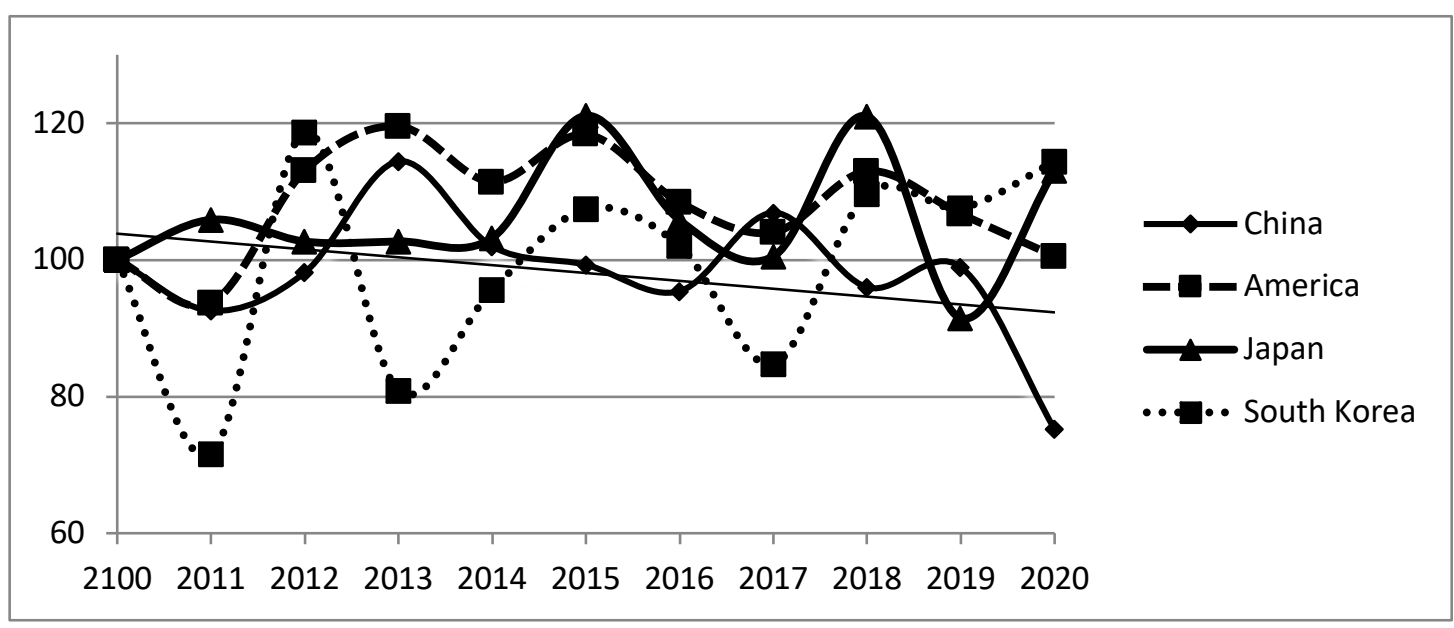

Figure 3 Technical Factor Index

Table 4 Technical element results

\begin{tabular}{cccccccccccccc}
\hline & 2010 & 2011 & 2012 & 2013 & 2014 & 2015 & 2016 & 2017 & 2018 & 2019 & 2020 \\
\hline China & 100.00 & 92.57 & 98.14 & 114.42 & 101.97 & 99.28 & 95.42 & 106.89 & 95.99 & 98.91 & 75.21 \\
America & 100.00 & 93.68 & 113.04 & 119.54 & 111.41 & 118.37 & 108.41 & 104.02 & 112.97 & 106.70 & 100.53 \\
Japan & 100.00 & 105.87 & 102.68 & 102.70 & 103.21 & 121.09 & 105.80 & 100.51 & 121.00 & 91.46 & 113.06 \\
South Korea & 100.00 & 71.59 & 118.72 & 80.91 & 95.57 & 107.46 & 102.06 & 84.75 & 109.67 & 107.62 & 114.37 \\
\hline
\end{tabular}

It can be seen from Figure 4 that China's market factor index was in a relatively stable state of development from 2010 to 2017, declined in 2018, and then gradually recovered to the original stable state, showing an upward trend. In 2018, the intensification of the Sino-US trade war had a greater impact on China's wireless communications industry. At the same time, the wireless communications industries in the United States, Japan, and South Korea were also affected to varying degrees. In 2020, the "Global Wireless Communication Network Technology Invention Patent Ranking" jointly released by IPRdaily and incoPat Innovation Index Research Center shows that Huawei Technologies Co., Ltd. has 8,607 patents, ranking first, while Qualcomm (US) has 5,807 patents. It can be seen that China's influence in the international market of the wireless communication industry is getting stronger and stronger. There were two troughs in the US market factor index, in 2011 and 2018. In 2011, the US "Super Committee" failed to reduce the deficit, and Congress was almost paralyzed, resulting in a slow economic recovery. At the same time, the European debt crisis has increased the uncertainty of the U.S. economic outlook and further led to an economic downturn in the wireless communications industry. In 2018, the trade war also 
exacerbated the extent of the U.S. economic downturn. During the entire observation period, Japan's market factor index fluctuates slightly and is basically in a stable state, which is a stable development. Compared with Japan's relatively stable market factor index, South Korea's market factors have a greater degree of volatility. In general, they show a "W"-shaped development state. There was a relative trough point in 2015 and 2018, and a relative peak in 2016. point. In 2015, the scale of South Korea's ICT industry increased by $1.3 \%$, but its revenue declined compared to 2014, mainly because mobile phones replaced fixed-line phone services. However, in 2016, with the deregulation of the communications industry, the scale of ICT increased by $1.6 \%$ year-on-year, which greatly improved the economic development level of the wireless communications industry.

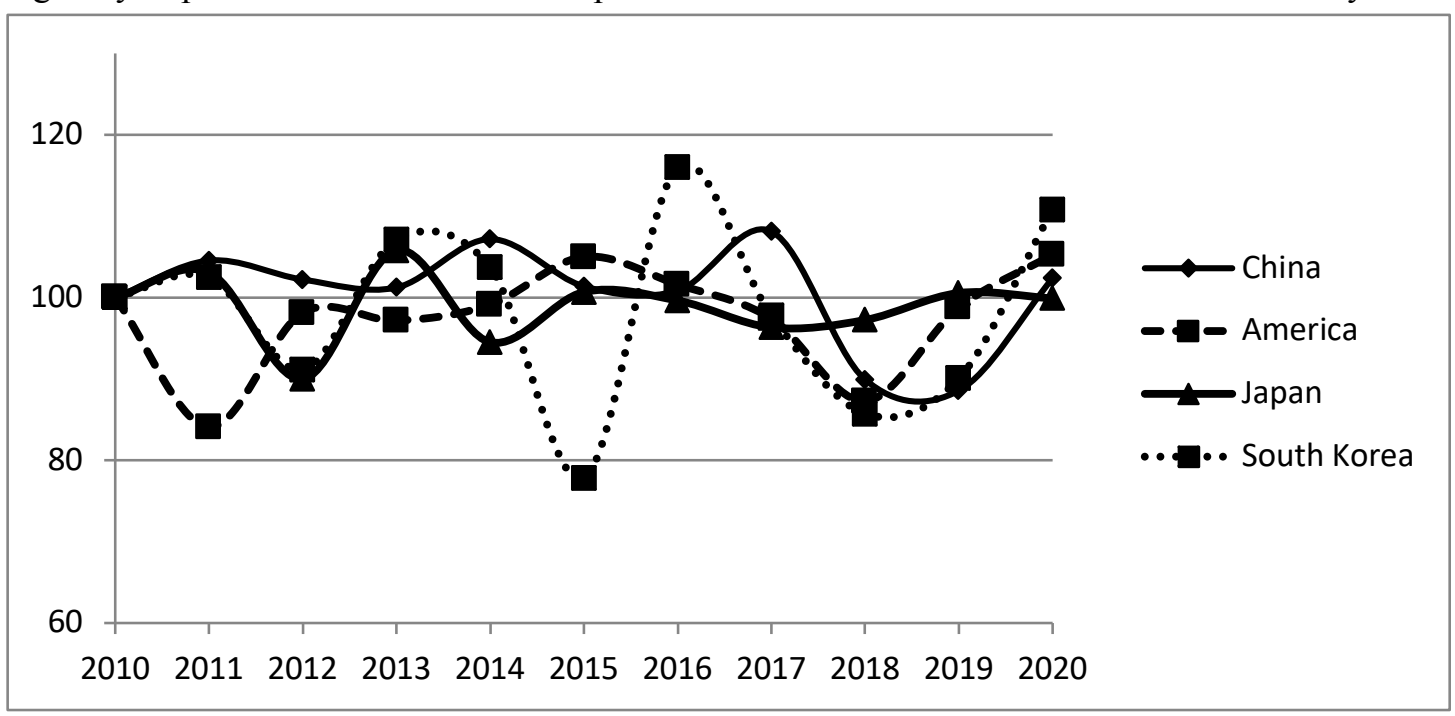

Figure 4 Market Factor Index

Table 5 Results of market factors

\begin{tabular}{ccccccccccccc}
\hline & 2010 & 2011 & 2012 & 2013 & 2014 & 2015 & 2016 & 2017 & 2018 & 2019 & 2020 \\
\hline China & 100.00 & 104.54 & 102.21 & 101.23 & 107.18 & 101.38 & 100.84 & 108.12 & 89.92 & 88.58 & 102.36 \\
America & 100.00 & 84.09 & 98.14 & 97.17 & 99.12 & 105.00 & 101.60 & 97.42 & 87.27 & 98.77 & 105.26 \\
Japan & 100.00 & 103.08 & 89.99 & 105.81 & 94.51 & 100.68 & 99.63 & 96.32 & 97.24 & 100.56 & 99.90 \\
South Korea & 100.00 & 102.51 & 91.11 & 107.10 & 103.72 & 77.80 & 116.00 & 97.77 & 85.72 & 90.06 & 110.83 \\
\hline
\end{tabular}

It can be seen from Figure 5 that China's legal factor index has generally shown a downward trend in volatility, and there have been three relative peaks during the decline, respectively in 2013, 2016 and 2019. There are two main reasons for the decline in the volatility of legal elements in China: First, the difference between the growth of patent scale and its value level. Since China promulgated the "Patent Law" in 1984, the country has invested a lot of financial and material resources in patents, which has led to an explosive increase in the number of patent applications. However, many invention patents have been directly abandoned without meeting the 20-year protection period. It shows that the level of patent value is low, which directly caused a large number of low-value patents; second, the degree of patent protection. Patent authorization is limited to the country/region where the patent is filed. In other countries/regions, it is difficult to form corresponding legal effects due to high maintenance costs, fierce technical competition, and complex market environment. This further increases the difficulty for my country's patents to be protected in the international market. From 2011 to 2018, the legal elements of the United States were relatively stable. Since 2018, the curve of U.S. legal elements has shown an upward trend. 
"U.S. Federal Information and Communication Technology (ICT) Supply Chain Addressing China's Vulnerability" (2018), "US Internet Industry Report 2019" and "IT Industry Outlook 2020" show that Wireless communication technology is becoming the main driving force of the global information technology industry, and the US information technology industry accounts for $32 \%$ of the world market, ranking first. Japan's and South Korea's legal element indexes are generally relatively consistent, with relative peaks in 2011, 2013, 2016, and 2019, respectively. However, in 2015, South Korea's decline was relatively large, mainly due to technological iterations in the communications industry (mobile communications replace fixed communications) have led to a number of existing patented technologies being in a state of failure, thereby weakening the degree of protection of patented technologies abroad.

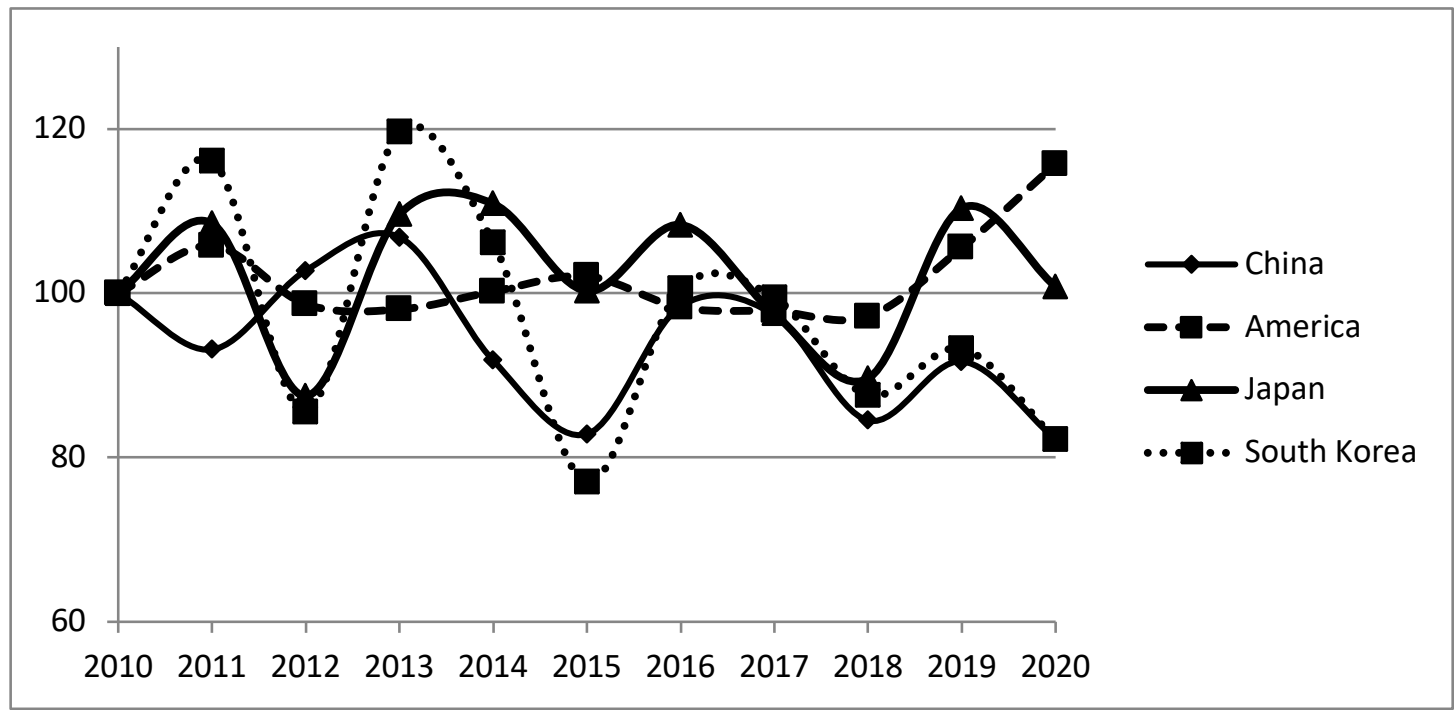

Figure 5 Index of Legal Elements

Table 6 Results of legal elements

\begin{tabular}{lllllllllllll}
\hline & 2010 & 2011 & 2012 & 2013 & 2014 & 2015 & 2016 & 2017 & 2018 & 2019 & 2020 \\
\hline China & 100.00 & 93.16 & 102.77 & 106.84 & 91.83 & 82.86 & 98.43 & 97.37 & 84.52 & 91.71 & 82.20 \\
America & 100.00 & 105.80 & 98.68 & 98.04 & 100.22 & 102.08 & 98.27 & 97.83 & 97.19 & 105.57 & 115.75 \\
Japan & 100.00 & 108.51 & 87.51 & 109.61 & 110.91 & 100.29 & 108.34 & 97.51 & 89.65 & 110.38 & 100.81 \\
South Korea & 100.00 & 116.14 & 85.55 & 119.72 & 106.18 & 77.01 & 100.58 & 99.49 & 87.58 & 93.30 & 82.20 \\
\hline
\end{tabular}

It can be seen from Figure 6 that China's technology lock-in index has generally shown a downward trend in volatility, and the rate of decline has accelerated after 2017, indicating that China's certain core technology areas of wireless communication are more vulnerable to technology lock-in by foreign economies. From a technical perspective, the dependence of technological development and the traction of technological tracks are the technological factors that form the lock-in effect. Although China implemented the "Broadband China" strategy and issued 4G licenses in 2013, certain breakthroughs have been made in the field of information and communications. However, foreign economies control the core technologies in the field of wireless communications and maintain a 1-2 generation technological gap with China (Take EUV extreme ultraviolet lithography machine as an example), making it difficult for my country to make independent technological breakthroughs in the wireless communications industry. Compared with China, the technology lock-in of the United States, Japan, and South Korea has generally shown an upward trend of volatility. Among them, the United States began to accelerate 
in 2018, followed by Japan and South Korea. The rising side of the technology lock-in index of the United States, Japan, and South Korea also reflects their greater control over core technologies in the field of wireless communication technology. From an economic perspective, various alliance models and economic behaviors in industrial organizations are the economic factors that form the lock-in effect. For example, the Dutch ASML company has monopolized the high-end products and core technologies of lithography machines at various stages by formulating strategic alliance contracts, establishing technical cooperation, exchanges and other industrial alliances. In 2019, under pressure from the United States, it seized two China's the $7 \mathrm{~nm}$ lithography machine has locked the core technology of China's chip field. According to the viewpoint of law and economics, the optimal validity period of a patented technology is when the social cost and social benefits of the patented technology reach a balance. However, most of China's patents were abandoned by the property owners before the expiry date, which caused China to invest a large amount of research and development funds in the field of wireless communications, but produced a large number of low-value patents. From a legal perspective, the relationship between property rights and behavior constraints are the legal factors that form the lock-in effect. After clarifying the innovation property rights, all parties in the market seek lower-cost property rights institutional arrangements in the market through property rights contracts, so as to encourage technological innovators to obtain a rate of return close to the social rate of return from the innovation property rights. Economists believe that institutional factors (non-technical factors) are decisive factors for economic growth. The entire process of technological innovation is based on institutional innovation, and the key to institutional innovation lies in the innovation of the property right system. The effective period of patented technology property rights in the field of information and communication in China is generally 3 to 5 years (only $17 \%$ of the patent rights for innovative technologies terminated in the United States after 3 years), and the elimination rate is relatively fast, resulting in the low efficiency of technical innovation property rights in the field of wireless communications in China. Patented technologies in the international market require higher maintenance costs to restrict other counterfeit technologies to increase their degree of protection, but because of their low value level, It is difficult for patent owners to pay higher maintenance costs, which weakens the behavioral constraints of patented technologies in the international market.

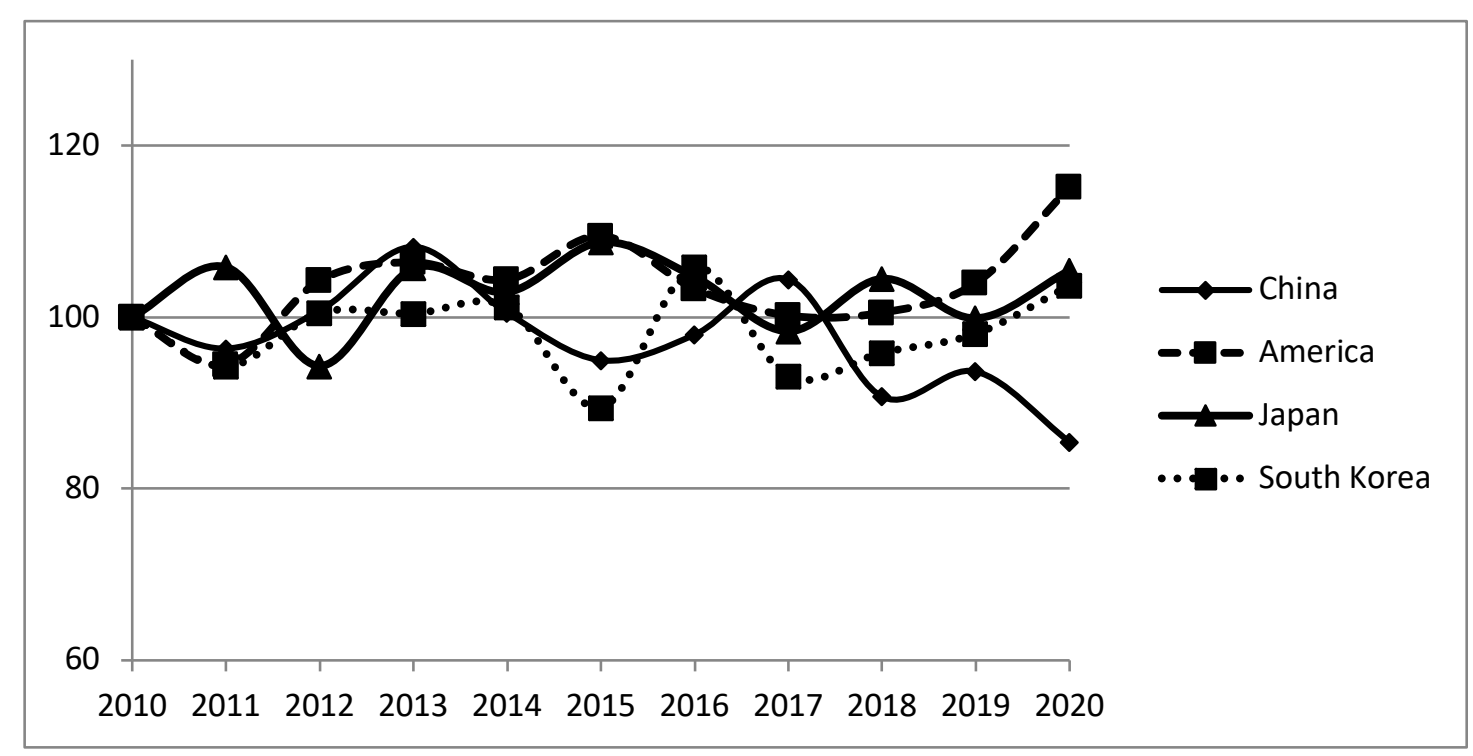


Figure 6 Technology Lock-in Index

Table 7 Technical lock-in results

\begin{tabular}{|c|c|c|c|c|c|c|c|c|c|c|c|}
\hline & 2010 & 2011 & 2012 & 2013 & 2014 & 2015 & 2016 & 2017 & 2018 & 2019 & 2020 \\
\hline China & 100.00 & 96.34 & 100.75 & 108.19 & 100.49 & 94.98 & 97.95 & 104.40 & 90.73 & 93.65 & 85.45 \\
\hline $\begin{array}{c}\text { Degree } \\
\text { of }\end{array}$ & $\begin{array}{l}\text { Initial } \\
\text { value }\end{array}$ & Lower & $\begin{array}{c}\text { Modera } \\
\text { tely }\end{array}$ & Higher & $\begin{array}{c}\text { Modera } \\
\text { tely }\end{array}$ & Lower & Lower & $\begin{array}{c}\text { Modera } \\
\text { tely }\end{array}$ & Low & Lower & Low \\
\hline \multicolumn{12}{|l|}{ lock-in } \\
\hline America & 100.00 & 94.44 & 104.26 & 106.38 & 104.37 & 109.47 & 103.32 & 100.18 & 100.52 & 103.98 & 115.13 \\
\hline $\begin{array}{c}\text { Degree } \\
\text { of }\end{array}$ & $\begin{array}{l}\text { Initial } \\
\text { value }\end{array}$ & Lower & $\begin{array}{c}\text { Modera } \\
\text { tely }\end{array}$ & Higher & $\begin{array}{c}\text { Modera } \\
\text { tely }\end{array}$ & Higher & $\begin{array}{c}\text { Modera } \\
\text { tely }\end{array}$ & $\begin{array}{c}\text { Modera } \\
\text { tely }\end{array}$ & $\begin{array}{c}\text { Modera } \\
\text { tely }\end{array}$ & $\begin{array}{c}\text { Modera } \\
\text { tely }\end{array}$ & Height \\
\hline \multicolumn{12}{|l|}{ lock-in } \\
\hline Japan & 100.00 & 105.83 & 94.32 & 105.70 & 102.91 & 108.72 & 104.71 & 98.35 & 104.47 & 99.87 & 105.44 \\
\hline $\begin{array}{c}\text { Degree } \\
\text { of }\end{array}$ & $\begin{array}{l}\text { Initial } \\
\text { value }\end{array}$ & $\begin{array}{c}\text { Modera } \\
\text { tely }\end{array}$ & Lower & $\begin{array}{c}\text { Modera } \\
\text { tely }\end{array}$ & $\begin{array}{c}\text { Modera } \\
\text { tely }\end{array}$ & Higher & $\begin{array}{c}\text { Modera } \\
\text { tely }\end{array}$ & Lower & $\begin{array}{c}\text { Modera } \\
\text { tely }\end{array}$ & $\begin{array}{c}\text { Modera } \\
\text { tely }\end{array}$ & Higher \\
\hline lock-in & & & & & & & & & & & \\
\hline $\begin{array}{l}\text { South } \\
\text { Korea }\end{array}$ & 100.00 & 94.23 & 100.49 & 100.41 & 101.20 & 89.43 & 105.80 & 93.08 & 95.86 & 98.06 & 103.66 \\
\hline $\begin{array}{c}\text { Degree } \\
\text { of }\end{array}$ & $\begin{array}{l}\text { Initial } \\
\text { value }\end{array}$ & Lower & $\begin{array}{c}\text { Modera } \\
\text { tely }\end{array}$ & $\begin{array}{c}\text { Modera } \\
\text { tely }\end{array}$ & $\begin{array}{c}\text { Modera } \\
\text { tely }\end{array}$ & Low & $\begin{array}{c}\text { Modera } \\
\text { tely }\end{array}$ & Lower & Lower & Lower & $\begin{array}{c}\text { Modera } \\
\text { tely }\end{array}$ \\
\hline lock-in & & & & & & & & & & & \\
\hline
\end{tabular}

\subsection{Core technology identification}

Through the core patent identification of wireless communication network patents, it can be seen that only 6 patents have scores between $[70 \%, 100 \%], 129$ patents in $[30 \%, 70 \%)$, and the number of $[0 \%, 30 \%)$ has 77,831 patents. It can be seen that the higher the core technology evaluation index score, the fewer the number of patents, and the core technology evaluation index score presents a normal distribution trend on the right side, and the long tail effect is obvious. It can be seen from Table 6 that the 6 core patents selected are all US corporate patents and are mainly concentrated from 2015 to 2019. It can be seen that enterprises play an important role in the field of wireless communication networks. Among them, the number one patent is US10278167B2, which describes receiving control messages for the WTRU in the radio resource space. From the perspective of the main classification number, the core patents are mainly concentrated in the three core patents of H04W72/04, H04W72/08 and H04L1/00, of which H04W72/04 is the same data transmission method and user equipment; H04W72/08 is in the LTE network Signaling for proximity service and D2D discovery; H04L1/00 is a method and device for providing channel allocation information for supporting uplink and downlink channels.

Table 6 Core Patents

\begin{tabular}{lcccccc}
\hline $\begin{array}{l}\text { Seri } \\
\text { al }\end{array}$ & public account & $\begin{array}{c}\text { Public } \\
\text { year }\end{array}$ & $\begin{array}{c}\text { nati } \\
\text { on }\end{array}$ & Applicant name/type & $\begin{array}{c}\text { Main } \\
\text { IPC/LOC }\end{array}$ & Patent subject \\
ber & & & & & & \\
\hline 1 & US10278167B2 & 2019 & US & Qualcomm/enterprise & H04W72/ & Radio resources, \\
& & & & & 04 & WTRU control
\end{tabular}




\begin{tabular}{|c|c|c|c|c|c|c|}
\hline 2 & US10237854B2 & 2019 & US & InterDigital/enterprise & H04L1/00 & $\begin{array}{l}\text { Link channel, } \\
\text { allocation information }\end{array}$ \\
\hline 3 & $\begin{array}{l}\text { US2017035984 } \\
1 \mathrm{~A} 1\end{array}$ & 2017 & US & $\begin{array}{c}\text { EVOLVED WIRELESS } \\
\text { LLC/enterprise }\end{array}$ & $\begin{array}{l}\text { H04W72/ } \\
04\end{array}$ & $\begin{array}{c}\text { Data transmission } \\
\text { method, user } \\
\text { equipment }\end{array}$ \\
\hline 4 & US9634801B2 & 2017 & US & $\begin{array}{l}\text { INTERDIGITAL/enterpri } \\
\text { se }\end{array}$ & H04B1/69 & $\begin{array}{c}\text { User equipment } \\
\text { identification, specific } \\
\text { interference }\end{array}$ \\
\hline 5 & US9788186B2 & 2015 & US & $\begin{array}{c}\text { InTML IP } \\
\text { Corporation/enterprise }\end{array}$ & $\begin{array}{l}\text { H04W72/ } \\
10\end{array}$ & $\begin{array}{l}\text { LTE network, D2D } \\
\text { signaling }\end{array}$ \\
\hline 6 & US10321294B2 & 2016 & US & $\begin{array}{c}\text { InTML IP } \\
\text { Corporation/enterprise }\end{array}$ & $\begin{array}{l}\text { H04W72/ } \\
08\end{array}$ & $\begin{array}{l}\text { LTE network, D2D } \\
\text { signaling }\end{array}$ \\
\hline
\end{tabular}

\section{Conclusion and inspiration}

Through in-depth analysis of patent-intensive industries, an integrated theoretical analysis model of "technology-market-law" (TML analysis model) was constructed, and the patented technologies of wireless communication networks in China, the United States, Japan, and South Korea were used as research objects to clarify the formation mechanism of technology lock-in, Decouple and measure technology lock-in, provide a theoretical basis and analysis method for cracking my country's "technical lock-in", and then achieves the goal of a "patent-powered nation". The conclusions are as follows:

Research conclusions: (1) The technology lock-in index of the United States, Japan, and South Korea generally shows an upward trend, while the technology lock-in index of China has a trend of decreasing volatility, and the United States has the highest degree of lock-in in the field of wireless communication network technology, in the first place, Japan and South Korea are in the second and third positions, respectively, and China is in the fourth. This shows that although my country has established a patent pool in the field of wireless communications, some core technologies in this field are still subject to foreign developed countries. In addition, the rise in the technology lock-in index of the United States, Japan, and South Korea also reflects their greater control over core technologies in the field of wireless communication technology. The main reason is that in the early development process ( $1 \mathrm{G}$ and $2 \mathrm{G}$ era) in the field of wireless communication networks in China, China was over-reliant on foreign core technologies. As a result, China was led by foreign technology tracks when establishing independent core technologies. It is root cause of the lock-in effect. Industrial alliances under economic behavior are the direct cause of technology lock-in. When the social costs and benefits of the patented technology reach an equilibrium point, the multi-party entities will form an alliance of interests during the optimal validity period of the patent to build technical barriers, causing the lock-up and lock-in competition between the technology owner and the subsequent technology user. The entire process of technological innovation is based on institutional innovation, and the key to institutional innovation lies in the innovation of the property right system. The definition of patent property rights is the institutional reason for the formation of technology lock-in. Only the patented technology after the property right has legal effect. Therefore, market entities through clarification of property rights contracts and institutional arrangements for the property rights of core technologies constitute core technology lock-in and obtain monopolistic social profits; (2) The six core technologies identified belong to US companies, and the public year is concentrated 
in 2017 and In 2019, the technical field is concentrated on the three core patents of H04W72/04, H04W72/08 and H04L1/00, of which H04W72/04 is the same data transmission method and user equipment; H04W72/08 is the LTE network for proximity services and the signaling of D2D discovery; H04L1/00 is a method and device for providing channel allocation information for supporting uplink and downlink channels, indicating that the current three core technologies are cutting-edge technologies in the field of wireless communication networks.

Policy enlightenment: (1) In the technological dimension, it is mainly based on the dependence of technological development and the traction of technological track, and in response to technological development trends such as break innovation and technology leap appearing in the industry, the R\&D structure of core technologies should be further optimized, promote the establishment of a sustainable core technology R\&D investment mechanism led by public financial resources. The core technology represents the frontier direction of this technology field and is the fundamental factor in promoting the upgrading of patent-intensive industries. The sustainable core technology R\&D mechanism is the key to promoting patent-intensive industries to solve the foreign technology lock-in dilemma. Patent-intensive industries should use current core technologies as technological breakthroughs, public financial resources as technical guarantees, and improve the incentive mechanism between all parties, so as to drive social funds led by financial funds to form an all-round, multi-subject, patent-intensive industry upgrade and transformation pattern, and solve the foreign "technology lock-in" dilemma, to crack foreign technology lock-in; (2) From the market dimension, grasp the characteristics of patent-intensive industries at each stage of technological evolution, and clarify the government, industry, universities and scientific research institutions, to build a diversified technology collaboration ecosystem. The systemic issues in patent-intensive industry technology lock-in have strengthened the necessity for government, industry, university, research and research to jointly participate in solving the technology lock-in dilemma. In the process of cracking the technology lock-in, although the government has a lot of financial resources, its function is limited. It is necessary to accurately grasp the characteristics of patent-intensive industries in the technological evolution stage, focus on breaking technology locks, strengthen investment in science and technology, and further promote core technology research and original innovation. Patent-intensive industries should improve the efficiency of resource allocation in the R\&D process of core technologies, give full play to their own economic advantages, and stimulate the enthusiasm of new technology research and development. As the promoters of cracking technology lock-in, universities and scientific research institutions should closely integrate with patent-intensive industries, jointly participate in the research and development of new technologies, and create an inclusive technological atmosphere. In the process of cracking the technology lock-in, all parties have an irreplaceable camera role. According to the differences in the development of technology at various stages, a diversified technology collaboration ecosystem should be established and improved; (3) In the legal dimension, improving the intellectual property legal system and stabilize the expected return on core technologies in patent-intensive industries. The process of breaking the technology lock-in itself has the characteristics of high investment, high risk and low return. Based on patent property rights and behavioral constraints, the focus is on the cooperation and competition between the core technology owner and the subsequent technology owner formed by different property rights relationships of technology lock-in and anti-technology lock-in. By improving the intellectual property legal system, clarifying the conditions and paths for the 
transformation of patented technology property rights, effectively guaranteeing the legal property rights and expected innovation benefits of core technology owners, and urging them to mobilize more resources in the process of cracking the technology lock-in. Through the improvement of patents, we can obtain cross-licensing with basic patents with core technologies, and then formulate the implementation rules and related policies of the patent law, and realize the regulation of excessive technology lock-in behavior.

\section{References}

Garcilazo E, Moreno-Monroy AI, Martins J O. Regional inequalities and contributions to aggregate growth in the 2000s: an EU vs US comparison based on functional regions [J]. Oxford Review of Economic Policy, 2021, 37(1 ): 70-96.

Liu H, Chen Z, Tang J, Zhou Y, Liu S. Mapping the technology evolution path: a novel model for dynamic topic detection and tracking [J]. Scientometrics, 2020(2):1-48.

Li Baizhou, Wang Dan. The dynamic efficiency measurement and temporal evolution of patent-intensive industries in my country[J]. Studies in Science of Science, 2020, 38(11): 1987-1997.

Wang X, Liu Y, Chen L. Innovation Efficiency Evaluation Based on a Two-Stage DEA Model With Shared-Input: A Case of Patent-Intensive Industry in China [J]. IEEE Transactions on Engineering Management, 2021, (99):1-15.

He Ningxin, Dong Zhelin. Quantitative model and empirical research on the intensity of patent judicial protection[J]. Scientific Research Management, 2020, 41(02): 115-122.

Feng S, Ma X. To Increase Damages of InTMLlectual Property Infringement in China: A Double-Edged Sword for the Market [J]. Journal of world trade, 2019, 53(1):39-58.

Gilbert R J. Competition, Mergers, and R\&D Diversity [J]. Review of Industrial Organization, 2019, 54(3):465-484.

Mo J Y. Technological innovation and its impact on carbon emissions: evidence from Korea manufacturing firms participating emission trading scheme [J]. Technology Analysis and Strategic Management, 2021(1):1-11.

Zhao Yuntong, Du Yushen. Research on the technology lock-in effect of technology entanglement and interest association[J]. Research in Science of Science, 2020, 38(10): 1800-1810.

Ejderyan O, Ruef F, Stauffacher M. Entanglement of Top-Down and Bottom-Up: Sociotechnical Innovation Pathways of Geothermal Energy in Switzerland [J]. The Journal of Environment \& Development, 2020, 29(1):99- 122.

Sun Guoqiang, Shi Wenping, Yu Yanqin, Zhang Hongbing. Technical power, inter-organizational trust and cooperative behavior: A study on leadership-following behavior based on the Qinshui coalbed methane network [J]. Nankai Management Review, 2019, 22(01): 87-97.

Wang Juan, Zhang Peng. Research on the "lock-in effect" of manufacturing technology spillover breakthroughs under the background of service transformation[J]. Research in Science of Science, 2019, 37(02): 276-290.

Fehder D C, Murray F, Stern S. InTMLlectual property rights and the evolution of scientific journals as knowledge platforms [J]. International Journal of Industrial Organization, 2014, 36:83-94.

Li Liming. Recognition of patent-intensive industries: a new analytical framework[J]. Science and Technology Progress and Policy, 2020, 37(16): 72-80. 
Qi X, Feng Y. A Method of Patent Thicket Detection Based on Patent Citation Density: the Black Hole Effect in a Patent Pool [J]. Journal of InTMLligence, 2015, 221(4):269-274.

Fischer T, Ringler P. The coincidence of patent thickets-A comparative analysis [J]. Technovation, 2015, 38:42-49.

Li Liming, Chen Mingyuan. Patent-intensive industries, patent system and economic growth[J]. China Soft Science, 2017(04):152-168.

Du Chuanzhong, Wang Mengchen. Research on the Impact of Skill-biased Technological Progress on the Ascent of China's Manufacturing Value Chain__ Based on the Perspective of Intellectual Property Protection[J]. Economic Science, 2021(01): 31-43.

Arthur W B. Competing Technologies, Increasing Returns, and Lock in by Historical Events $[\mathrm{J}]$. The Economic Journal, 1989, 99, (394):116-131.

David PA. Clio and the Economics of Qwerty $[\mathrm{J}]$. American Economic Review, 1985,75(2):332-337.

Daghfous A, White G R. Information and innovation: a comprehensive representation [J]. Research Policy, 1994, 23(3):267-280.

Saito You. Invention Patent Economics [M]. Beijing: Patent Literature Press, 1990: 168-170.

Zhang Mier, Li Haipeng, Guowei. Research on the Construction and Evaluation of the Quality Index of Patent Internationalization [J]. Scientific Research Management, 2019, 40(08): 189-197.

Marco C, Myriam M, Salvatore T. Firm strategic behavior and the measurement of knowledge flows with patent citations [J]. Strategic Management Journal, 2019, 40(7):1040-1069.

Yang $\mathrm{Wu}$, Sun Shiqiang, Xu Hongdan. Measurement and identification of industrial competitive advantage based on TML model: Taking the fuel cell industry as an example [J/OL]. Information Magazine, 2021, (06):1-9.

W. J. Abernathy and J. M. Utterback, Patterns of Industrial Innovation. [J]. MIT Technology Review, 1975, 80, (07): 2-9.

Rosenbloom R S, Abernathy W J. The climate for innovation in industry: The role of management attitudes and practices in consumer electronics [J]. Research Policy, 1982, 11(4):209-225.

Danielle L, D Charlotta, Jan K, Per L. Applying patent survival analysis in the academic context[J]. Research Evaluation, 2015(2):1-16.

Gong Richao, Pan Fenping. The calculation model of the possibility degree of interval numbers under non-uniform distribution and its application [J]. Chinese Management Science, 2020, 28(12): 220-230. 